\title{
Effect of electrostatic charge, flow, delay and multiple actuations on the in vitro delivery of salbutamol from different small volume spacers for infants
}

Johannes H Wildhaber, Sunalene G Devadason, Ernst Eber, Mark J Hayden, Mark L Everard, Quentin A Summers, Peter N LeSouëf

\begin{abstract}
Background - A study was undertaken to determine the influences of electrostatic charge, flow, delay, and multiple actuations on the in vitro delivery of salbutamol generated by a pressurised metered dose inhaler (pMDI) from small volume spacers used in infants.

Methods - Ten actuations from a salbutamol pMDI were drawn at different flow rates after either single or multiple actuations, with or without delay, through either static or reduced static spacers. An ionic detergent was used to reduce the charge of plastic spacers (Babyhaler, Babyspacer, Aerochamber, Nebuhaler). Electrostatic charge was measured using an electrometer. A multistage liquid impinger was used to determine the particle size distribution of the output of the pMDI through the spacers.
\end{abstract}

Results - Electrostatic charge on the surface of plastic spacers had the greatest influence on delivery, causing a decrease in drug delivery. Reducing charge by coating the surface with ionic detergent resulted in an increase of $46.5-71.1 \%(p<0.001)$ in small $(<6.8 \mu \mathrm{m})$ particle delivery from small volume plastic spacers. Lower flow, delay, and multiple actuations resulted in decreased delivery from static spacers. Lower flow resulted in a decrease of $15 \%$ in small $(<9.6 \mu \mathrm{m})$ particle delivery. Delay and multiple actuations resulted in a decrease of $40.7 \%$ and $76.0 \%$, respectively, in small $(<6.8 \mu \mathrm{m})$ particle delivery. The influences of lower flow, delay, and multiple actuations were greatly reduced or even eliminated by reducing charge. However, multiple actuations still resulted in a significant decreased delivery $(p<0.05)$. The reduced static Nebuhaler had a higher delivery than all small volume spacers.

Conclusions - Electrostatic charge has a major influence on the delivery of salbutamol from small volume spacers. Using a metal spacer or ionic detergent coating of plastic spacers resulted in no or reduced charge and hence in improved delivery. Lower flow, delay, and multiple actuations played a major part only in static spacers. (Thorax 1996;51:985-988)

Keywords: inhalation devices, aerosol therapy, electrostatic charge.
Spacers were created to overcome coordination problems in the use of pressurised metered dose inhalers (pMDI). ${ }^{12}$ The main purpose of a spacer device is to enable the discharged aerosol cloud to be held in a chamber reservoir. Large volume spacers are used for drug administration in adults and children over four years of age. ${ }^{3}$

The breathing pattern of infants is different from adults and older children, with high breathing frequencies, low inspiratory flows, and small tidal volumes. Small volume spacers were designed for use in infants. ${ }^{45}$ The advantage of a small volume spacer is that it can be cleared more easily by smaller tidal volumes. ${ }^{6}$

Until recently all spacers were made of plastic; this led to the build up of an electrostatic charge on the surface of the aerosol resulting in reduced drug delivery by attraction of the aerosol. ${ }^{7}$ To avoid the effect of charge on delivery a steel spacer was developed. ${ }^{8}$

Electrostatic charge, delay of inhalation, and multiple actuations have been shown to influence the delivery from large volume spacers, ${ }^{9-11}$ so we have investigated the effects of charge, flow, delay, and multiple actuations on small volume spacers used in infants.

\section{Methods}

Delivery of salbutamol generated by a pMDI (Ventolin, Allen and Hanburys, Australia) through three small volume plastic spacers (Babyhaler, Glaxo, Switzerland, $350 \mathrm{ml}$; Babyspacer, Astra, Denmark, $250 \mathrm{ml}$; Aerochamber, Trudell, Canada, $165 \mathrm{ml}$ ) and a small volume metal spacer (Nebuchamber, Astra, Sweden, $250 \mathrm{ml}$ ) was measured and compared with drug delivery through a large volume plastic spacer (Nebuhaler, Astra, Sweden, $750 \mathrm{ml}$ ).

To determine the effect of charge the plastic spacers were either rubbed with a piece of clear plastic to induce a high charge (static spacers) or immersed in diluted (1:250 with water) ionic detergent (Liquid Pyroneg, Diversey, Australia) for one hour and subsequently drip dried for 24 hours to reduce charge by coating the inner surface with detergent (reduced static spacers). The electrostatic charge was measured using a slightly modified electrometer (Electronic Instruments Ltd, Model 37C; Jacoby Mitchell, Sydney, Australia). The $35 \mathrm{ml}$ ionisation chamber was replaced by a metal \\ Research Group,
}


Table 1 Mean (SD) and range of amount of particles of $<6.8 \mu \mathrm{m}$ delivered to stages 3 and 4 as a percentage of the total actuated dose for the different spacers at static and reduced static conditions

\begin{tabular}{llllll}
\hline & Babyhaler & Babyspacer & Aerochamber & Nebuhaler & Nebuchamber \\
\hline Static & $32.9(1.45) \%$ & $30.3(2.87) \%$ & $32.1(2.06) \%$ & $31.0(3.02) \%$ & - \\
Reduced static & $(31.1-34.6)$ & $(27.8-34.4)$ & $(29.6-34.6)$ & $(28.4-35.1)$ & \\
& $(54.3(2.05) \%$ & $44.4(1.45) \%$ & $47.9(2.03) \%$ & $63.7(0.94) \%$ & $52.6(4.69) \%$ \\
& $(54.59 .0)$ & $(42.7-46.1)$ & $(45.8-49.9)$ & $(62.5-64.8)$ & $(48.4-57.4)$ \\
\hline
\end{tabular}

electrode of area $20 \mathrm{~mm} \times 19 \mathrm{~mm}$. Its surface was insulated by a $0.8 \mathrm{~mm}$ thick piece of Teflon. The electrometer gave a reading in roentgens which could be converted into coulombs (C) using the relationship 1 roentgen $=7.0 \mathrm{nC}$. The surface charge density was calculated by dividing the measured charge by the electrode area of $3.8 \times 10^{-4} \mathrm{~m}^{2}$.

The spacer was attached to a high performance multistage liquid impinger (MSLI, Copley, Nottingham, UK). Air was drawn through this system at a continuous flow rate of $60 \mathrm{l} / \mathrm{min}$. The salbutamol pMDI was shaken for 30 seconds and two actuations were wasted prior to testing. Ten actuations were then introduced into the spacer with five second intervals between each actuation. The pMDI was shaken vigorously in the intervals between actuations.

In addition, the following procedures were performed for the Nebuchamber and the static and reduced static Babyhaler:

To determine the effect of flow, drug delivery was also measured at flow rates of $10 \mathrm{l} / \mathrm{min}$ and $30 \mathrm{l} / \mathrm{min}$. The size distributions at a flow rate of $10 \mathrm{l} / \mathrm{min}$ were measured by mixing the flow from the spacer $(10 \mathrm{l} / \mathrm{min})$ with clean air at a flow rate of $20 \mathrm{l} / \mathrm{min}$.

To assess the effect of delay on drug delivery, the continuous flow of $60 \mathrm{l} / \mathrm{min}$ was opened one, five, or 20 seconds after each actuation of the pMDI.

Drug delivery was measured after 10 single actuations at a continuous flow rate of $60 \mathrm{l} /$ min, after five times two actuations, and after two times five actuations before opening the flow of $60 \mathrm{l} / \mathrm{min}$ immediately after the last actuation, respectively.

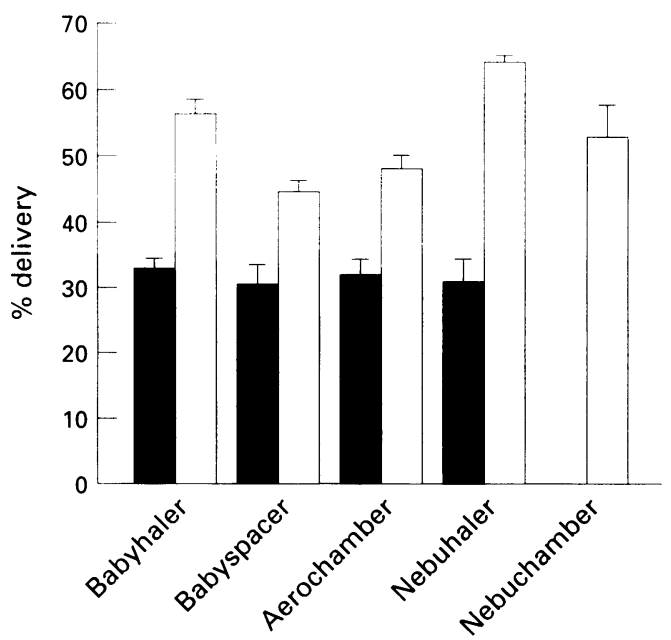

Figure 1 Mean (SD) delivery of particles of $<6.8 \mu \mathrm{m}$ as a percentage of the total actuated dose for the different spacers in static ( $\square$ ) and reduced static ( $\square$ ) conditions.
After actuating the pMDI the aerosol was drawn through the device with the entraining air flow. Droplets were deposited on the actuator, the throat, or one of the four stages. The total amount of the actuated drug was determined by the total recovery from the actuator, the spacer, the throat, and the four stages. The site of deposition in the MSLI was determined by the particle size of the droplets. The MSLI had been calibrated by the manufacturer (Astra Draco, Sweden) so that particles of $>13 \mu \mathrm{m}, 6.8-13 \mu \mathrm{m}, 3.1-6.8 \mu \mathrm{m}$, and $<3.1 \mu \mathrm{m}$ for a flow rate of $60 \mathrm{l} / \mathrm{min}$, and $>18.4 \mu \mathrm{m}, \quad 9.6-18.4 \mu \mathrm{m}, 4.4-9.6 \mu \mathrm{m}$, and $<4.4 \mu \mathrm{m}$ for flow rates of $301 / \mathrm{min}$ and $10 \mathrm{l} /$ min were deposited on stages $1,2,3$, and 4 , respectively.

The actuator, spacer, throat, and each of the stages of the MSLI were separately washed with $40 \mathrm{ml}$ of methanol. Five $\mathrm{ml}$ of $0.1 \mathrm{M} \mathrm{NaOH}$ was added to each wash and the volume was then made up to $50 \mathrm{ml}$ with methanol. The absorbance (wavelength $246 \mathrm{~nm}$ ) of each sample was measured in duplicate on a spectrophotometer (Hitachi U-2000, Japan). The concentration of salbutamol in each sample was obtained by using the absorbance of a standard solution containing a known concentration of salbutamol. The standard curve for salbutamol was linear $\left(r^{2}=1.00\right)$ for concentrations between 0 and $21 \mu \mathrm{g} / \mathrm{ml}$.

Each experiment was repeated four times and all measurements were undertaken under constant atmospheric conditions. The mean temperature was $22.6^{\circ} \mathrm{C}$ (range $21.8-24.7^{\circ} \mathrm{C}$ ) and mean barometric pressure was $760 \mathrm{mmHg}$ (range $750-768 \mathrm{mmHg}$ ).

Statistical analysis was carried out using analysis of variance (ANOVA) with a significance level of $95 \%(\mathrm{p}<0.05)$.

\section{Results}

The electrostatic charge for static spacers was 3.3-6.7 $\mu \mathrm{C} / \mathrm{m}^{2}$ and for reduced static spacers was $0-1.2 \mu \mathrm{C} / \mathrm{m}^{2}$.

The mean (range) of the total actuated dose was $1096 \mu \mathrm{g}(1071-1111 \mu \mathrm{g})$ for the static

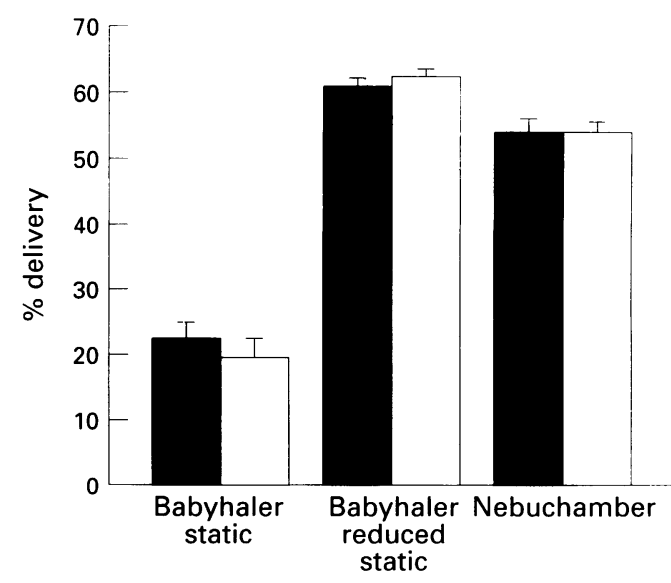

Figure 2 Mean (SD) delivery of particles of $<9.6 \mu \mathrm{m}$ as a percentage of the total actuated dose at flow rates of 30 $\mathrm{l} / \mathrm{min}(\square)$ and $10 \mathrm{l} / \mathrm{min}(\square)$ for the static and reduced static Babyhaler and the Nebuchamber. 
Table 2 Mean (SD) and range of amount of particles of $<9.6 \mu \mathrm{m}$ diameter at flow rates of $10 \mathrm{l} / \mathrm{min}$ and $30 \mathrm{l} / \mathrm{min}$ and particles of $<6.8 \mu \mathrm{m}$ at a flow rate of $60 \mathrm{l} / \mathrm{min}$ delivered to stages 3 and 4 as a percentage of the total actuated dose for the static and reduced static Babyhaler and for the Nebuchamber

\begin{tabular}{|c|c|c|c|}
\hline Flow rate & Static Babyhaler & $\begin{array}{l}\text { Reduced static } \\
\text { Babyhaler }\end{array}$ & Nebuchamber \\
\hline \multicolumn{4}{|l|}{ Particles $<9.6 \mu \mathrm{m}$ : } \\
\hline $101 / \mathrm{min}$ & $\begin{array}{l}19.2(2.92) \% \\
(18.5-20.1)\end{array}$ & $\begin{array}{l}62.4(0.67) \% \\
(60.9-64.5)\end{array}$ & $\begin{array}{l}54.1(1.52) \% \\
(52.2-58.4)\end{array}$ \\
\hline $301 / \mathrm{min}$ & $\begin{array}{l}22.6(2.52) \% \\
(21.9-23.2)\end{array}$ & $\begin{array}{l}60.8(0.55) \% \\
(59.7-63.4)\end{array}$ & $\begin{array}{l}54.1(1.68) \% \\
(51.9-57.7)\end{array}$ \\
\hline \multicolumn{4}{|l|}{ Particles $<6.8 \mu \mathrm{m}:$} \\
\hline $601 / \min$ & $\begin{array}{l}32.9(1.45) \% \\
(31.1-34.6)\end{array}$ & $\begin{array}{l}56.3(2.05) \% \\
(54.3-57.2)\end{array}$ & $\begin{array}{l}52.6(4.69) \% \\
(48.4-57.4)\end{array}$ \\
\hline \multicolumn{4}{|l|}{ Delay } \\
\hline 1 second & $\begin{array}{l}19.5(1.91) \% \\
(17.5-22.8)\end{array}$ & $\begin{array}{l}57.2(1.40) \% \\
(55.2-58.3)\end{array}$ & $\begin{array}{l}53.6(3.33) \% \\
(49.0-56.9)\end{array}$ \\
\hline 5 seconds & $\begin{array}{l}12.3(0.58) \% \\
(11.7-13.1)\end{array}$ & $\begin{array}{l}55.2(1.49) \% \\
(53.5-56.9)\end{array}$ & $\begin{array}{l}49.9(1.86) \% \\
(48.2-52.5)\end{array}$ \\
\hline 20 seconds & $\begin{array}{l}8.6(1.01) \% \\
(7.8-10.1)\end{array}$ & $\begin{array}{l}53.7(1.16) \% \\
(52.1-54.7)\end{array}$ & $\begin{array}{l}49.8(2.33) \% \\
(47.2-52.8)\end{array}$ \\
\hline \multicolumn{4}{|l|}{ Multiple puffs (flow $60 \mathrm{l} / \mathrm{min}$ ) } \\
\hline 2 puffs & $\begin{array}{l}16.3(1.55) \% \\
(14.1-18.4)\end{array}$ & $\begin{array}{l}53.4(1.40) \% \\
(51.5-54.9)\end{array}$ & $\begin{array}{l}48.8(1.63) \% \\
(46.6-50.4)\end{array}$ \\
\hline 5 puffs & $\begin{array}{l}11.2(1.24) \% \\
(10.4-13.2)\end{array}$ & $\begin{array}{l}53.3(1.30) \% \\
(51.9-54.9)\end{array}$ & $\begin{array}{l}48.6(1.52) \% \\
(46.6-50.3)\end{array}$ \\
\hline
\end{tabular}

Babyhaler, $1160 \mu \mathrm{g}(1070-1208 \mu \mathrm{g})$ for the reduced static Babyhaler, $1133 \mu \mathrm{g}$ (1086$1212 \mu \mathrm{g})$ for the static Babyspacer, $1043 \mu \mathrm{g}$ $(979-1098 \mu \mathrm{g})$ for the reduced static Babyspacer, $1047 \mu \mathrm{g}(1032-1063 \mu \mathrm{g})$ for the static Aerochamber, $1014 \mu \mathrm{g}(960-1078 \mu \mathrm{g})$ for the reduced static Aerochamber, $991 \mu \mathrm{g}$ $(980-1023 \mu \mathrm{g})$ for the static Nebuhaler,

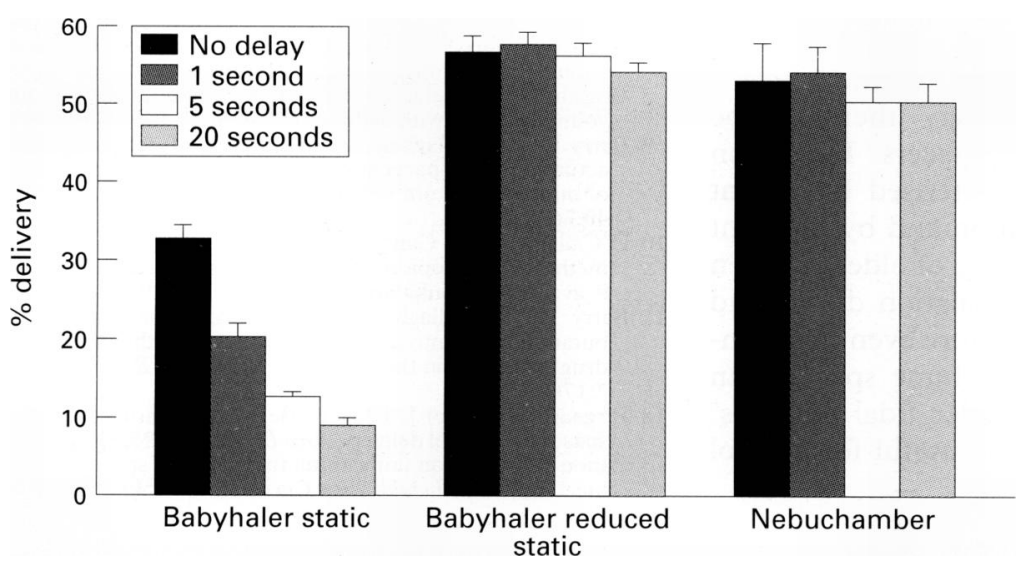

Figure 3 Mean (SD) delivery of particles of $<6.8 \mu \mathrm{m}$ as a percentage of the total actuated dose with different delays for the static and reduced static Babyhaler and for the Nebuchamber.

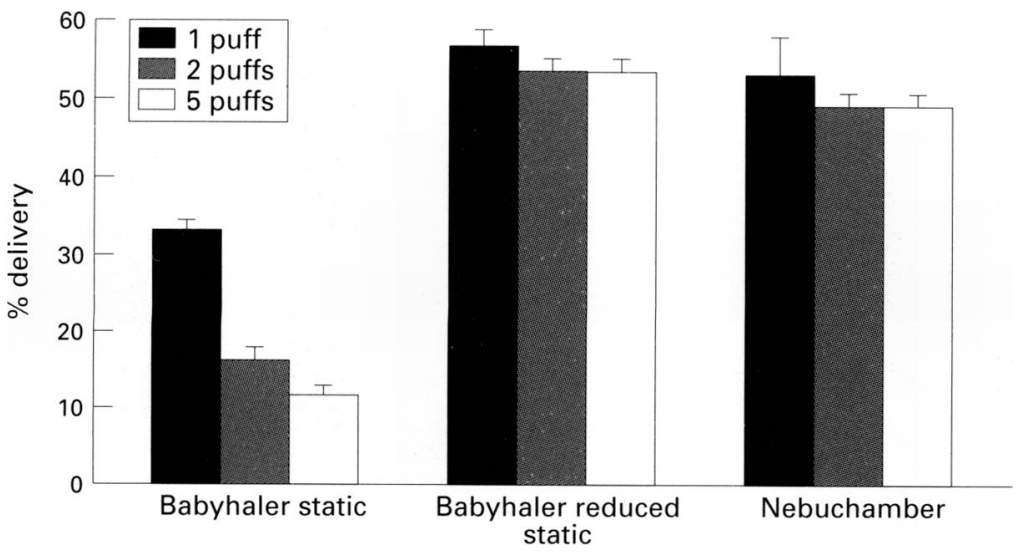

Figure 4 Mean (SD) delivery of particles of $<6.8 \mu \mathrm{m}$ as a percentage of the total actuated dose with multiple actuations for the static and reduced static Babyhaler and for the Nebuchamber.
$1074 \mu \mathrm{g}(994-1150 \mu \mathrm{g})$ for the reduced static Nebuhaler, and $1050 \mu \mathrm{g}(1015-1075 \mu \mathrm{g})$ for the Nebuchamber.

Table 1 shows the amount of particles of $<6.8 \mu \mathrm{m}$ delivered to stages 3 and 4 as a percentage of the total actuated dose for the different spacers at static and reduced static conditions. There was no significant difference in drug delivery from different static plastic spacers. The Nebuchamber had a higher delivery $(\mathrm{p}<0.001)$ than all static plastic spacers (fig 1). However, compared with reduced static plastic spacers, this effect was reduced or eliminated. The reduced static Nebuhaler had a higher delivery than all reduced static small volume plastic spacers $(\mathrm{p}<0.001)$ and the Nebuchamber $(p<0.001)$. The reduced static Babyhaler had a higher delivery than the reduced static Babyspacer $(p<0.001)$, the reduced static Aerochamber $(\mathrm{p}<0.001)$, and the Nebuchamber $(\mathrm{p}<0.05)$.

Table 2 shows the amounts of particles of $<9.6 \mu \mathrm{m}$ for flow rates of $10 \mathrm{l} / \mathrm{min}$ and $30 \mathrm{l} / \mathrm{min}$ and particles of $<6.8 \mu \mathrm{m}$ for a flow rate of $60 \mathrm{l} /$ min delivered to stages 3 and 4 as a percentage of the total actuated dose for the static and reduced static Babyhaler and the Nebuchamber.

Drug delivery at a flow rate of $30 \mathrm{l} / \mathrm{min}$ was similar to that at $10 \mathrm{l} / \mathrm{min}$ for the reduced static Babyhaler and the Nebuchamber. However, drug delivery at $301 / \mathrm{min}$ was higher $(p<0.05)$ than at $10 \mathrm{l} / \mathrm{min}$ for the static Babyhaler (fig 2).

Delay resulted in lower drug delivery in the static Babyhaler (fig 3). The decrease in delivery of particles of $<6.8 \mu \mathrm{m}$ for a delay of one second was $13.4 \%$ of the total amount $(p<0.001)$ compared with $20.6 \%(p<0.001)$ for a delay of five seconds and $24.3 \%(\mathrm{p}<0.001)$ for a 20 second delay. Delay had no significant effect on drug delivery with the reduced static Babyhaler and the Nebuchamber.

Multiple actuations also resulted in a significant decrease in drug delivery for the static Babyhaler (fig 4). The decrease in delivery of particles of $<6.8 \mu \mathrm{m}$ for two puffs was $16.6 \%(\mathrm{p}<0.001)$ and for five puffs was $21.7 \%$ $(p<0.001)$ of the total amount, respectively. Differences in drug delivery from the reduced static Babyhaler and the Nebuchamber for multiple actuations were less pronounced but still significant $(\mathrm{p}<0.05$ and $\mathrm{p}<0.01$, respectively).

\section{Discussion}

Electrostatic charge was the major influence on delivery of salbutamol generated by a pMDI from plastic spacers. In addition, low flow, delay, and multiple actuations resulted in decreased delivery from static spacers. Their effect was greatly reduced or even eliminated by reducing the charge, although multiple actuations still resulted in a significant decrease in delivery. For drug delivery from reduced static spacers the volume and the shape appear to be the most important factors.

The most likely explanation for these results is the increased residence time of the aerosol within the spacer with lower flow, increased 
delay, and multiple actuations. The amount of aerosol attracted to the spacer surface by the electrostatic charge depends on the time between actuation of the pMDI into the spacer and clearing of the spacer.

Our results can be of practical consequence. As charge is the major factor which decreases delivery, it is very important to avoid it. Recent studies have shown that charge is reduced on a plastic spacer by using an antistatic lining. ${ }^{79}$ This may not be a practical treatment for spacers used by patients. Conducting materials carry no electrostatic charge, so a spacer made of steel solves the problem of reduced drug delivery due to electrostatic charge. ${ }^{8} \mathrm{~A}$ recent study has shown that a metal spacer is superior to plastic spacers, even if electrostatic charge is reduced on the surface of a plastic spacer. ${ }^{12}$ However, the authors did not measure the electrostatic charge and therefore did not prove that priming a plastic spacer with multiple actuations before use effectively reduces the charge. In contrast, we have shown that the problem of electrostatic charge is solved by coating a plastic spacer with an ionic detergent for 24 hours. This procedure greatly reduced the electrostatic charge - probably by the build up of a conducting layer on the spacer surface. This effective and practical treatment improved delivery from plastic spacers.

Delivery from reduced static spacers was mostly dependent on the volume and the shape of the spacer. The actuated aerosol cloud is held more efficiently in a large volume spacer. ${ }^{13}$ A large volume spacer may therefore be superior to small volume spacers. Inhalation therapy in infants is characterised by absent compliance and coordination and by different breathing patterns from those of older children and adults. An optimal inhalation device and inhalation method are therefore even more important in infants. Small volume spacers can be cleared easily with smaller tidal volumes ${ }^{6}$ and have been shown to be useful for aerosol therapy in infants. ${ }^{45}$
Inspiratory flow rates in infants are likely to be less than $10 \mathrm{l} / \mathrm{min}$. Our results can therefore be directly applied to children over two years of age as their inspiratory flow rates are likely to be over $10 \mathrm{l} / \mathrm{min}$. However, our finding that the delivery from static spacers is decreased with lower flow rates may suggest that the effect on delivery of flow rates of less than $101 / \mathrm{min}$ would be even greater.

Compliance and coordination problems in inhalation therapy in infancy may result in delays between actuation and inhalation and also in multiple actuations. These factors greatly influenced the drug delivery from static spacers only. The use of a reduced static spacer may allow improved inhalation therapy in infants as the influences of low flow, delay, and multiple actuations are greatly reduced or even eliminated.

1 Kim CS, Eldridge MA, Sackner MA. Oropharyngeal deposition and delivery aspects of metered dose inhaler position and delivery aspects of metered do

2 König P. Spacer devices used with metered-dose inhalers, break through or gimmick? Chest 1985;88:276-84

3 Levison H, Reilly PA, Worsley GH. Spacing devices and metered-dose inhalers in childhood asthma. $\mathcal{f}$ Pediatr 1985;107:662-8.

4 Kraemer R, Birrer P, Modelska K, Casaulta Aebischer C, Schöni MH. A new baby-spacer device for aerosolized bronchodilator administration in infants with bronchopulmonary disease. Eur $¥$ Pediatr 1992;151:57-60.

5 Kraemer R, Frey U, Wirz Sommer C, Russi E. Short-term effect of albuterol, delivered via a new auxiliary device, in effect of albuterol, delivered via a new auxiliary device,

6 Everard ML, Clark AR, Milner AD. Drug delivery from Everard ML, Clark AR, Milner AD. Drug delivery from
holding chambers with attached facemask. Arch Dis Child 1992;67:580-5

7 O'Callaghan CO, Lynch J, Cant M, Robertson C. Improvement in drug delivery from spacer devices by use of an anti-static lining. Thorax 1993;48:603-6.

8 Bisgaard $\mathrm{H}$. A metal aerosol holding chamber devised for young children with asthma. Eur Respir f 1995;8:856-60.

9 Barry PW, O'Callaghan CO. The effect of delay, multiple actuations and spacer static charge on the in vitro delivery of budesonide from nebuhaler. Br f Clin Pharmacol 1995; 40:76-8.

10 O'Callaghan CO, Cant M, Robertson C. Delivery of beclomethasone dipropionate from a spacer device: what dose is available for inhalation? Thorax 1994;49:961-4

11 Barry PW, O'Callaghan CO. Multiple actuations of salbutamol MDI into a spacer device reduce the amount of drug recovered in the respirable range. Eur Respir f 1994 7:1707-9.

12 Bisgaard H, Anhøj J, Klug B, Berg E. A non-electrostatic spacer for aerosol delivery. Arch Dis Child 1995;73:226-30.

13 Zanon P. Inhalation antiasthma therapy with spacers: technical aspects. Monaldi Arch Chest Dis 1994;49:258-64. 